nâng cao chất lượng dịch vụ khám chữa bệnh Nghiên cứu tại Khoa Khám bệnh, Bệnh viện Hữu nghị Việt Đức'". Tap chí Công thương,

3. Lề Thị Kim Ngần, Lê Thị Thu Trang (2014) "Đánh giá mức độ hài lòng của bênh nhân điêu trị nội trú về chất lượng dịch vụ tại Bệnh viện đa khoa Trung Ương Cần Thơ ". Tạp chí Khoa học Trường Đại học Cân Thơ, Phân D: Khoa học Chính trị, Kinh tế và Pháp luật, 31, 8-16.

4. Nguyễn Văn Thắm (2018) Chất lượng dịch vụ chăm sóc da tại khoa Khám, Bênh viện Da liêuu thành phố Cần Thơ và một số yếu tố ẳnh hưởng năm 2018, Quản lý bệnh viện, Trường Đại học Y tế công cộng,

5. Rula Al-Damen (2017) "Health Care Service Quality and Its Impact on Patient Satisfaction -
Case of Al-Bashir Hospital'"'. International Journal of Business and Management, 12 (9)

6. Mohammad-Hossein Biglu, Farnaz Nateq Morteza Ghojazadeh, Ali Asgharzadeh (2017) "Communication Skills of Physicians and Patients' Satisfaction". Materia socio-medica, 29 (3), 192-195.

7. Z. Dong, M. R. Phillips (2008) "Evolution of China's health-care system". Lancet, 372 (9651), 1715-6.

8. Arab M Ghazi Tabatabaei $S$ Rashidian A Rahimi Forushani A Zarei E (2012) "The Effect of Service Quality on Patient loyalty a Study of Private Hospitals in Tehran, Iran-annotatedannotated". Iranian Journal of Public Health, 41 (9) 71-77.

\title{
KẾT QUẢ MộT Số CAN THIỆPY TẾ CÔNG CộNG VÀ RÀO CẢN ẢNH HƯỞNG TỚI CÔNG TÁC SÀNG LỌC, CHẨN ĐOÁN VÀ ĐIỀU TRI LAO TIỀM ẨN TẠI HAI TỈNH QUẢNG NAM, ĐÀ NÃ̃NG
}

\author{
Lương Anh Bình ${ }^{1}$, Nguyễn Thu Anh ${ }^{2}$, Greg $\mathrm{Fox}^{2,3}$, Trần Ngọc Bửu ${ }^{2}$, \\ Lưu Ngọc Hoạt ${ }^{4}$, Nguyễn Viết Nhung ${ }^{1}$ \\ chống lao Quốc gia.
}

TÓM TẮT

Nghiên cứu can thiêp về thực trang chẩn đoán và điều trị lao tiềm ẩn taii hai tỉnh Quảng Nam, Đà Nẵng và kết quả một số giải pháp can thiệp được thực hiện nhằm đánh giá kết quả một số can thiệp y tế công cộng trong việc tăng số người tiếp xúc được sàng lọc, chẩn đoán và điều trị lao tiềm ẩn. Phân tích chuôi đa bậc quản lý lao tiềm ẩn (cascade) về kêt quả tại địa bàn can thiệp cho thấy trong 1.623 người tiếp xúc được nhận diện, $65,6 \%$ (1.064) thực tế đến cơ sở y tế tham gia sàng loc, $65,4 \%(1.062)$ hoàn thành sàng loc, $46,8 \%$ (760) hoàn tất thẩm định y khoa, $33,8 \%$ (548) được chỉ đinh điều trị lao tiềm ẩn, và $29,9 \%$ (485) tiến hành điều trị lao tiềm ẩn. Rào cản ảnh hưởng đến tỷ lệ người tiếp xúc không tham gia chuỗi đa bậc gồm hạn chế nhận thức về lao, lao tiềm ẩn, kỳ thi và tự kỳ thi, thói quen tìm kiếm dich vu chăm sóc sức khoẻ của người dân, thuận tiện và chất lượng của dịch vụ y tế, v.v. Kết quả của nghiên cứu cho thấy việc triển khai các can thiệp y tế công cộng giúp tăng số người tiếp xúc tham gia vào chuối dịch vụ đa bậc quản lý lao tiềm ẩn khi so sánh với số liệu trước can thiệp và số liệu của địa bàn đối chứng, và do đó, sẽ khả thi khi mở rộng các can thiệp quản lý lao tiềm ẩn như là một chương trình ưu tiền trong Chương trình

\footnotetext{
${ }^{1}$ Bênh viện Phổi Trung ương

2Viên NC Y khoa Woolcock

${ }^{3}$ Trường Đại hoc Sydney, Australia

4Trướng Đại hoc Y Hà Nôii

Chịu trách nhiệm chính: Lương Anh Bình

Email: luonganhbinh.vntp@gmail.com

Ngày nhận bài: 9/1/2021

Ngày phản biên khoa hoc: 29/1/2021

Ngày duyệt bài: $1 / 3 / 2021$
}

Tư khóa: Lao tiềm ẩn, bệnh nhân lao phổi có bằng chứng vi khuẩn, người tiếp xúc hộ gia đình (NTX), xét nghiệm Mantoux, can thiệp y tế công cộng, Chương trình chống lao.

\section{SUMMARY \\ RESULTS OF PUBLIC HEALTH INTERVENTIONS \\ AND BARRIERS AFFECTING LATIENT TUBERCULOSIS INFECTION SCREENING, DIAGNOSIS AND TREATMENT AT TWO PROVINCES OF QUANG NAM, DANANG}

A pragmatic cluster randomized trial of Latent Tuberculosis Infection (LTBI) diagnosis and treatment at the two provinces of Quang Nam and Danang and the results of public health interventions was conducted to evaluate the results of public health interventions for individuals who are screened, diagnosed, and treated for LTBI. By cascade analysis at the intervention sites, 1.623 household contacts were listed, in which, 65,6\% (1.064) visited to district health centers for LTBI screening, 65,4\% (1.062) completed the screening, $46,8 \%$ (760) completed medical examinations, $33,8 \%$ (548) was recommended to start LTBI therapy, and $29,9 \%$ (485) started LTBI therapy. Barriers affecting drops-out at each step of the cascade included limited knowledge of TB and LTBI, perceived stigma, habits in seeking health services, etc. The research results showed that public health interventions helped in increasing percentage of household contacts' participation in each step of LTBI management cascade when compared with the baseline data and with the control sites; which proved the feasibility of scaling up the LTBI intervention as one prioritized program in the NTP. 
Keywords: Latent Tuberculosis Infection (LTBI), bacteria-confirmed pulmonary TB, household contact, Mantoux testing, public health intervention, National Tuberculosis Control Program.

\section{I. ĐẠT VẤN ĐỀ}

Theo báo cáo của Tổ chức y tế thế giới, bệnh lao vẫn là nguyên nhân gây tử vong đứng hàng thứ 9 và là bệnh lây truyền gây tỷ lệ tử vong cao nhất, xếp trên cả HIV/AIDS. Mặc dù đã đạt được một số thành tựu đáng kể trong công tác chống lao trong thời gian qua, Việt Nam xếp thứ 11/30 quốc gia có gánh nặng bệnh lao cao nhất và có gánh năng lao kháng đa thuốc cao nhất. Để kiểm soát bệnh lao trên phạm vi toàn cầu, sàng lọc và điều trị lao tiềm ẩn cho nhóm nguy cơ, đă̆c biệt người tiếp xúc hộ gia đình với bênh nhân lao phổi có bằng chứng vi khuẩn hiện được xác định là một trong những yếu tố then chốt được tổ chức y tế khuyến cáo [1]. Tuy nhiên, ở Việt Nam, cho đến năm 2017, Chương trình chống lao quốc gia (CTCLQG) mới chỉ triển khai một vài can thiệp lao tiềm ẩn cho trẻ dưới 5 tuổi tiếp xúc hộ gia đình với bệnh nhân lao phổi, và kết quả của các can thiệp chưa được như mong đợi. Việt Nam cũng đã triển khai một số nghiên cứu quy mô nhỏ để ước tính gánh nặng lao tiềm ẩn trong nhóm đối tượng khác, cho thấy 36,5\% người tiếp xúc hô gia đình bênh nhân lao phổi ở Bình Định, 36,8\% NTX hộ gia đình với bệnh nhân lao kháng đa thuốc, 27,8\% cán bộ y tế được xác định mắc lao tiềm ẩn. Số liêu chỉ ra có tỷ lệ đáng kể người tiếp xúc bỏ cuộc tại các bước sàng locc, chỉ định điều trị và chấp nhận điều trị lao tiềm ẩn, v.v. [2,3].

Nhóm nghiên cứu đã triển khai một số can thiệp ở Quảng Nam và Đà Nẵng nhằm đánh giá tác động của can thiêp y tế công cộng trong viêc tăng số người tiếp xúc được sàng lọc, chẩn đoán và điều trị lao tiềm ẩn, xác định các rào cản dẫn đến vẫn còn một tỷ lệ bỏ không tham các giai đoạn của chuỗi đa bậc quản lý lao tiềm ẩn, từ đó khuyến cáo các giải pháp can thiệp.

\section{II. ĐỐI TƯợNG VÀ PHƯƠNG PHÁP NGHIÊN CứU}

2.1. Thiêt kế nghiên cứu. Nghiên cứu áp dụng thiết kế nghiên cứu can thiệp vào hệ thống cung cấp dịch vụ y tế. Bên cạnh đó, nghiên cứu định tính cũng được áp dụng để tìm hiểu các rào cản ảnh hưởng đển quản lý lao tiềm ẩn trên địa bàn nghiên cứu.

Nghiên cứu triển khai các can thiệp y tế công cộng từ tháng 7/2017 đến tháng 10/2019 trong nhóm người tiếp xúc hộ gia đình với bệnh nhân lao phổi được thu nhận từ tháng 7/2017 đến
12/2018 tại 4 huyện can thiệp: Tam Kỳ, Phú Ninh (tỉnh Quảng Nam), Sơn Trà, Liên Chiểu (thành phố Đà Nẵng).

Tại địa bàn can thiệp, một số can thiệp y tế công cộng sẽ được triển khai, bao gồm (i) đào tạo cán bộ y tế tuyến huyện và xã về quản lý lao tiềm ẩn, kỹ thuật tiêm Mantoux, (ii) truyền thông cộng đồng về lao tiềm ẩn, (iii) điều tra NTX với BN chỉ điểm, (iv) điều phối cung cấp dịch vụ 1 cửa sàng lọc và điều trị lao tiềm ẩn, (v) cung ứng thuốc, vật tư, hóa chất, tét Mantoux, (vi) phu cấp cho cán bô y tế tư vấn sàng lọc và điều trị lao tiềm ẩn thành công, (vii) hỗ trợ chi phí đi lại cho NTX đến TTYT sàng lọc lao tiềm ẩn, và (viii) giám sát và thu thập số liệu nghiên cứu hàng quý.

\section{2. Đối tượng và cỡ mẫu nghiên cứu.} Bệnh nhân lao phổi được xem là bệnh nhân chỉ điểm trong nghiên cứu, người tiếp xúc hộ gia đình với bềnh nhân chỉ điểm ở mọi lứa tuổi là đối tượng chính được triển khai can thiệp. Trong nghiên cứu này, người tiếp xúc hộ gia đình được định nghĩa là ngủ cùng nhà ít nhất một đêm trong một tuần với người mắc bệnh lao phổi, mới hoặc tái phát, trong thời gian 3 tháng trở lại đây; hoặc người tiếp xúc trong nhà ít nhất một tiếng mộtt ngày và ít nhất 5 ngày trong một tuần với người mắc bệnh lao phổi hoạt động, mới hoặc tái phát, trong thời gian 3 tháng trở lại đây.

Nghiên cứu áp dụng phân bổ ngẫu nhiên để chọn ra 4 huyện can thiệp, cõ̃ mầu được can thiệp là 1.623 người tiếp xúc với bệnh nhân chỉ điểm. Bên cạnh đó, nhóm nghiên cứu chọn chủ đích 24 người để phỏng vấn sâu, bao gồm cán bộ y tế, bệnh nhân chỉ điểm, người tiếp xúc để tìm hiểu các rào cản ảnh hưởng công tác chẩn đoán và điều trị lao tiềm ẩn ở người tiếp xúc hộ gia đình.

2.3. Biến số và chỉ số nghiên cứu. Kết quả được đo lường bao gồm: (i) tỷ lệ NTX với BN chì điểm được nhận diên so với số NTX ước tính, (ii) tỷ lệ NTX được tiến hành sàng lọc lao/lao tiềm ẩn, (iii) tỷ lệ NTX với BN chỉ điểm hoàn thành quy trình khám sàng lọc, (iv) tỷ lệ NTX tiến hành thẩm định y khoa, (v) tỳ lệ NTX hoàn thành thẩm định y khoa, (vi) tỷ lệ người mắc lao tiềm ẩn được phát hiện, (vii) tỷ lệ người mắc lao tiềm ẩn được đưa vào điêu trị, và (viii) tỷ lệ người mắc lao tiềm ẩn hoàn thành điều trị. Các kết quả nghiên cứu được thu thập và so sánh ở thời điểm trước - sau can thiệp tại địa bàn can thiệp, cũng như so sánh cắt ngang tại thời điểm sau can thiệp giữa địa bàn can thiệp và địa bàn đối chứng.

2.4. Quản lý và phân tích số liệu. Các số 
liệu định tính sẽ được phân tích theo các nhóm rào cản ảnh hưởng tới chẩn đoán và điều trị lao tiềm ẩn.

Số liêu định lượng sau khi thu thâp đã được nhập, làm sạch và quản lý bằng phần mềm EpiData và phân tích bằng phần mềm STATA 14.0. Các phân tích thống kê mô tả phù hợp đã được sử dụng, giá trị tần số, tỷ lệ được dùng để mô tả các biến phân loại.

2.5. Đạo đức nghiên cứu. Nghiên cứu tuân theo các quy định về đạo đức và đã được Hội đồng đạo đức của Trường Đại học McGill, Canada, Bộ Y tế, CTCLQG phê duyệt.

\section{KẾT QUẢ NGHIÊN CứU}

Trong quá trình triển khai nghiên cứu, có 524 bệnh nhân chỉ điểm tại 4 địa bàn can thiệp (Tam Kỳ, Phú Ninh thuộc tỉnh Quảng Nam, Sơn Trà, Liên Chiểu thuộc Đà Nẵng) được đăng ký điều trị, trong số đó, cán bộ y tế khai thác được thông tin về người tiếp xúc của 451 bệnh nhân, chiếm $86,1 \%$. Cán bộ y tế tuyến huyện nhận diện được 1.623 trên tổng số 1.572 người tiếp xúc hộ gia đình được ước tính (ước tính mổi bệnh nhân chỉ điểm có 3 người tiếp xúc). Trong số 1.623 người tiếp xúc được nhận diện, qua trao đổi ban đầu với nhân viên y tế, có 1.089 người tiếp xúc mong muốn được đến cơ sở y tế để được sàng lọc lao và lao tiềm ẩn, chiếm $67,1 \%$.

Tính trên tỷ lệ luỹ kế của toàn bộ chuỗi đa bâc quản lý lao tiềm ẩn trong nhóm người tiếp xúc hộ gia đình với bênh nhân chỉ điểm, chì $67,1 \%$ (1.089) trong số những người tiếp xúc được nhận diện bày tỏ mong muốn tham gia sàng lọc, 65,6\% (1.064) thực tế đến cơ sở y tế tham gia sàng loc, $65,4 \%(1.062)$ hoàn thành sàng lọc, bao gồm xét nghiệm Mantoux, 47,8\% (776) đủ điều kiện thẩm định y khoa (gồm những người tiếp xúc có kết quả xét nghiệm Mantoux dương tính ở bước sàng loc, hoăc có tiền sử lao hoặc lao tiềm ẩn, có dấu hiệu nghi lao cho dù kết quả xét nghiệm Mantoux âm tính, hoăc trẻ em dưới 5 tuổi), 47,2\% (766) bắt đầu thẩm đinh y khoa, 46,8\% (760) hoàn tất thẩm định y khoa, 33,8\% (548) được chỉ đinh điều trị lao tiềm ẩn, và $29,9 \%$ (485) tiến hành điều trị lao tiềm ẩn (Bảng 1).

Bảng 1. Chuỗi đa bậc quản lý lao tiềm ẩn trong nhóm người tiếp xúc hộ gia đình với bệnh nhân chi điểm (tỷ lệ luỹ kê)

\begin{tabular}{|c|c|c|c|c|c|c|c|}
\hline \multirow[b]{2}{*}{ Đặc điểm } & \multicolumn{2}{|c|}{ Tổng } & \multicolumn{2}{|c|}{ Đà Nằng } & \multicolumn{2}{|c|}{ Quảng Nam } & \multirow[b]{2}{*}{$\begin{array}{c}\text { p- } \\
\text { value }\end{array}$} \\
\hline & $\begin{array}{c}\text { Số } \\
\text { lượng }\end{array}$ & $\begin{array}{c}\text { \% } \\
\text { luỹ kế }\end{array}$ & $\begin{array}{c}\text { Số } \\
\text { lượng }\end{array}$ & $\begin{array}{c}\text { \% } \\
\text { luỹ kế }\end{array}$ & $\begin{array}{l}\text { Số } \\
\text { lượng }\end{array}$ & $\begin{array}{c}\text { \% } \\
\text { luỹ kế }\end{array}$ & \\
\hline Gđ1. Người tiếp xúc được nhận diện & 1623 & 100 & 1167 & 100.0 & 456 & 100.0 & - \\
\hline $\begin{array}{l}\text { Người tiếp xúc được nhận diện mong } \\
\text { muốn tham gia sàng lọc }\end{array}$ & 1089 & 67.1 & 770 & 66.0 & 319 & 70.0 & 0.255 \\
\hline Gđ2. Người tiếp xúc đến khám sàng lọc & 1064 & 65.6 & 758 & 65.0 & 306 & 67.1 & 0.412 \\
\hline Gđ3. Người tiếp xúc hoàn tất sàng lọc & 1062 & 65.4 & 758 & 65.0 & 304 & 66.7 & 0.514 \\
\hline $\begin{array}{l}\text { Gđ4. Người tiếp xúc đủ điều kiện thẩm } \\
\text { định y khoa }\end{array}$ & 776 & 47.8 & 579 & 49.6 & 197 & 43.2 & 0.02 \\
\hline $\begin{array}{l}\text { Gđ5. Người tiếp xúc bắt đầu thực hiện } \\
\text { thẩm định y khoa }\end{array}$ & 766 & 47.2 & 572 & 49.0 & 194 & 42.5 & 0.017 \\
\hline $\begin{array}{l}\text { Gđ6. Người tiếp xúc hoàn tất thẩm định y } \\
\text { khoa }\end{array}$ & 760 & 46.8 & 566 & 48.5 & 194 & 42.5 & 0.031 \\
\hline $\begin{array}{l}\text { Gđ7. Người tiếp xúc được chỉ định điều trị } \\
\text { Lao tiềm ẩn }\end{array}$ & 548 & 33.8 & 395 & 33.8 & 153 & 33.6 & 0.91 \\
\hline $\begin{array}{l}\text { Gđ8. Người tiếp xúc tiến hành điều trị Lao } \\
\text { tiềm ẩn }\end{array}$ & 485 & 29.9 & 361 & 30.9 & 124 & 27.2 & 0.139 \\
\hline $\begin{array}{l}\text { Gđ9. Người tiếp xúc hoàn thành điều trị } \\
\text { Lao tiềm ẩn }\end{array}$ & 416 & 25.6 & 328 & 28.1 & 88 & 19.3 & $\begin{array}{c}<0.00 \\
1\end{array}$ \\
\hline
\end{tabular}

Tại giai đoạn sàng lọc, trong số 1.064 người tiếp xúc tham gia sàng lọc, có 635 người tiếp xúc có kết quả xét nghiệm Mantoux dương tính $(59,7 \%), 390(36,6 \%)$ có kết quả Mantoux âm tính, và 39 $(3,7 \%)$ không phải thực hiện xét nghiệm Mantoux (nhóm trẻ em dưới 5 tuổi). Tỷ lệ dương tính ở Đà Nẵng cao hơn có ý nghĩa thống kê so với Quảng Nam, 62,4\% so với 52,9\% ( $p<0.001)$. Trung vị của đường kính nốt sần khi đọc kết quả xét nghiệm Mantoux của 4 địa bàn can thiệp là $7 \mathrm{~mm}$, khoảng phân vị là $9 \mathrm{~mm}$, hai số liệu này ở Đà Nẵng lần lượt là $8 \mathrm{~mm}$ và $9 \mathrm{~mm}$, rộng hơn có ý nghĩa thống kê của Quảng Nam là $5 \mathrm{~mm}$ và $6 \mathrm{~mm}(\mathrm{p}<0.001)$ (Bảng 2$)$. 
Bảng 2. Các kêt quả sàng locc, thẩm định y khoa của người tiếp xúc

\begin{tabular}{|c|c|c|c|c|}
\hline Đặc điểm & Total & Đà Nằng & Quảng Nam & p-value \\
\hline \multicolumn{5}{|c|}{ Kết quả Mantoux $(n=1064)$} \\
\hline Dương tính & $635(59,7)$ & $473(62,4)$ & $162(52,9)$ & \multirow{3}{*}{$<0,001$} \\
\hline Âm tính & $390(36,6)$ & $248(32,7)$ & $142(46,4)$ & \\
\hline Không làm & $39(3,7)$ & $37(4,9)$ & $2(0,7)$ & \\
\hline Trung vị (IQR) & $7,0(9,0)$ & $8,0(9,0)$ & $5,0(6,0)$ & $<0,001$ \\
\hline
\end{tabular}

Về kết quả điều trị của lô bệnh nhân lao tiềm ẩn là người tiếp xúc hộ gia đình với bệnh nhân chì điểm, 461/485 (85,8\%) hoàn tất phác đồ điều trị, 61 bỏ trị $(12,6 \%), 5$ ngưng trị chủ động do phản ứng bất lợi trong quá trình sử dụng thuốc, và $3(0,6 \%)$ chuyển điều trị.

Bảng 3. Kết quả điều trị bệnh nhân lao tiềm ẩn

\begin{tabular}{|c|c|c|c|c|c|}
\hline & Số lượng & Hoàn thành ĐT & Dừng ĐT vì PU bất lợi & Chuyển & Bỏ trị \\
\hline Tống & 485 & $416(85,8 \%)$ & $5(1 \%)$ & $3(0,6 \%)$ & $61(12,6 \%)$ \\
\hline
\end{tabular}

Tỷ lệ người tiếp xúc tham gia trong các bước của chuối cung cấp dịch vụ đa bậc quản lý lao tiềm ẩn cho thấy tỷ lệ bỏ cuộc cao nhất thuộc về giai đoạn 2 (đến cơ sở y tế để tham gia sàng loc), giai đoạn 4 (đủ điêuu kiện thẩm định y khoa), và giai đoạn 7 (được chỉ định điều trị lao tiềm ẩn) (Biểu đồ 1).

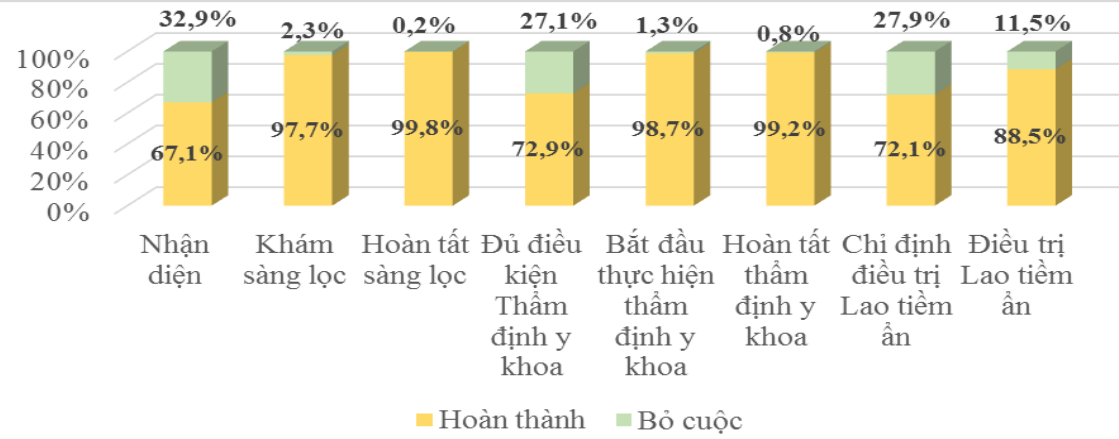

Biểu đồ 1. Tỷ lệ người tiếp xúc tham gia mỗi giai đoạn của chuỗi dịch vụ đa bậc quản lý lao tiềm ẩn

Kết quả phỏng vấn sâu chỉ ra một số rào cản ảnh hưởng đến tỷ lệ người tiếp xúc không tham gia các giai đoan của chuỗi dịch vu đa bậc quản lý lao tiềm ẩn. Đầu tiên là rào cản về phía dịch vụ y tế. Kết quả phỏng vấn sâu cho thấy cán bộ y tế chưa thực sự chú trọng vào công tác phát hiện và điều trị lao tiềm ẩn như mong đợi, chỉ xem các can thiệp quản lý lao tiềm ẩn đang triển khai là một hoạt động nghiên cứu, không phải là can thiệp thực sự cần thiết trong Chương trình chống lao. Cán bộ y tế huyện đôi khi không nhẫn nại, kiên trì thuyết phục người tiếp xúc đến cơ sở y tế để tham gia sàng lọc, thậm chí không trực tiếp liên hệ, mà giao nhiệm vụ này cho bệnh nhân chỉ điểm, và không quan tâm đến kết quả.

Rào cản thứ hai là hạn chế trong nhận thức về lao, lao tiềm ẩn. Cán bộ phụ trách lao tiềm ẩn ở trung tâm y tế huyện và cán bộ y tế nói chung mặc dù đã nắm rõ về quy trình thực hiện các giai đoạn trong chuỗi đa bậc quản lý lao tiềm ẩn, nhưng chưa thật sự có đủ thông tin về lao tiềm ẩn, đặc biệt, mơ hồ và chưa có lòng tin về hiệu quả của điều trị lao tiềm ẩn trong việc giảm thiểu khả năng phát triển thành bệnh lao đối với những người đã nhiễm lao. Trong 05 bệnh nhân chỉ điểm và 09 người tiếp xúc không tham gia hoặc không hoàn thành sàng lọc được phỏng vấn, có đến 5 người có hiểu biết khổng đúng hoặc không đầy đủ về bệnh lao, đường lây truyền bênh lao; và gần như tất cả đều chưa nghe nói đến lao tiềm ẩn, chỉ có duy nhất 01 người tiếp xúc mặc dù cho biết là chưa biết về lao tiềm ẩn.

Rào cản tiếp theo là vẫn tồn tại tình trang kỳ thị và tự kỳ thị đối với bệnh lao trong cộng đồng. Không nhiêu người bệnh mắc lao thoải mái chia sẻ tình trạng bệnh tật của mình cho hàng xóm, đồng nghiệp, bạn bè, do tự lo sơ bản thân sẽ bị xa lánh, phân biệt đối xử, nặng nề hơn ảnh hưởng đến cả công việc, thu nhập, các mối quan hệ của bản thân cũng như của gia đình mình "em cũng đang có người yêu nữa, em lo anh ây sợ lại xa lánh em". Thậm chí "nếu bảo đi khám thận, hay dạ dày, thì đi khám ngay, chứ bảo bệnh lao thì cứ thấy sợ sợ ... sợ họ sẽ xa lánh mình". Kỳ thị và tự kỳ thị đối với bệnh lao dẫn đến kết quả là bệnh nhân, người tiếp xúc hộ gia đình không muốn cán bộ y tế đến nhà tư vấn, 
thăm bệnh, lo ngại nguy cơ bị phát hiện có người thân mắc lao nếu đến cơ sở y tế để tham gia sàng lọc, cho dù là sàng lọc lao tiềm ẩn.

Một rào cản khác cũng được ghi nhận trong quá trình phỏng vấn cán bộ y tế, bệnh nhân chỉ điểm và người tiếp xúc, đó là thói quen trong hành vi tìm kiếm chăm sóc y tế của người dân. Một số người tiếp xúc chưa xây dựng thói quen tham gia sàng lọc bệnh tật để bảo vệ sức khoẻ bản thân, do đó, họ không đến cơ sở y tế khám chẩn đoán đớn giản chỉ do họ nhận thấy họ đang chưa có bất kỳ biểu hiện bệnh tật gì, hoăc nếu có thì chỉ là biểu hiện nhẹ nhàng, chưa nghiêm trọng.

Đối với giai đoạn điều trị, những rào cản từ phía người tiếp xúc dẫn đến còn một tỷ lệ đáng kể người tiếp xúc được chỉ định điêu trị lao tiềm ẩn từ chối điều trị $(11,5 \%)$ và một tỳ lệ bỏ trị trong số những bệnh nhân lao tiềm ẩn đã tiến hành điều trị $(12,6 \%)$ bao gồm (i) không tin tưởng hiệu quả điều trị lao tiềm ẩn, (ii) thời gian điều trị lao tiềm ẩn kéo dài ( 9 tháng sử dụng thuốc Isoniazid hàng ngày đối với người lớn và 6 tháng sử dung thuốc Isoniazid hàng ngày đối với trẻ em) của phác đồ điều trị lao tiềm ẩn mà Chương trình chống lao áp dụng ở giai đoạn triển khai nghiên cứu, và (iii) xảy ra phản ứng bất lợi của thuốc điều trị lao tiềm ẩn, mặc dù tỷ lệ này rất thấp.

\section{BÀN LUÂ̂N}

Việc triển khai các can thiệp đồng bô trên đia bàn can thiệp đã tạo nên một bước tiến vượt bậc so với giai đoạn trước khi triển khai can thiệp, chứng minh tác động tích cực của nghiên cứu, cụ thể, số người tiểp xúc tham gia sàng lọc trước can thiêp đạt $12,5 \%$, trong khi tỷ lệ này tại sau khi triển khai can thiệp đạt trên $65,6 \%$. Tuy nhiên, mặc dù có sự khác biệt có ý nghĩa thống kê khi so sánh giai đoạn trước và sau can thiệp, số liệu nghiên cứu cũng đã chỉ ra một kết quả chưa được như mong đợi về tỷ lệ người tiếp xúc tham gia và hoàn thành giai đoạn sàng lọc lao tiềm ẩn, cụ thể, 34,6\% người tiếp xúc hộ gia đình không đến cơ sở y tế để được sàng lọc lao và lao tiềm ẩn, tự bỏ qua cơ hội được phát hiện bệnh sớm và điều trị kịp thời, trong khi đây là một trong những nhóm dễ bị lây truyền bệnh lao cao nhất.

Những rào cản chính từ phía bệnh nhân chỉ điểm, người tiếp xúc dẫn đến tỷ lệ bỏ cuộc trong giai đoạn sàng lọc lao tiềm ẩn của chuỗi đa bậc được ghi nhận trong nghiên cứu bao gồm (i) hạn chể trong nhận thức về lao, lao tiềm ẩn, (ii) tình trạng kỳ thị và tự kỳ thị đối với bệnh lao, (iii) thói quen trong hành vi tìm kiếm dịch vụ $y$ tế và (iv) sự thuận tiện trong tiếp cận dịch vụ y tế cung cấp sàng lọc lao tiêm ẩn cũng đã được chỉ ra tương tự trong một nghiên cứu về các rào cản đối với tiếp nhận và điêu trị lao tiềm ẩn trong nhóm trẻ vị thành niên ở Hoa Kỳ, đánh giá trên nhóm bố me gốc Châu Mỹ La tinh [5]. Thói quen có bệnh mới chữa không chỉ được chỉ ra trong nghiển cứu ở Quảng Nam và Đà Nẵng, mà cũng được ghi chú trong nghiên cứu ở Brazil, khi 92,3\% cán bộ y tế cho biết những người không có triệu chứng không quan tâm đến chăm sóc dự phòng và $88,5 \%$ báo cáo có những trường hợp người tiếp xúc không đến tham gia quá trình sàng lọc do họ không có các triệu chứng của bệnh [5].

Tỷ lệ (luỹ kế) người tiếp xúc được xác định nhiễm lao tiềm ẩn trong nghiên cứu là $33,8 \%$, thấp hơn một chút so với kết quả từ phân tích dịch vụ đa bậc quản lý lao tiềm ẩn từ 58 nghiên cứu trên thế giới (35\%) [4], thấp hơn đáng kể so với tỷ lệ hiện mắc lao tiềm ẩn trong nhóm tiếp xúc hộ gia đình đã được tổng hợp trong một tổng quan hệ thống và phân tích gộp khác về điều tra người tiếp xúc để chẩn đoán lao và lao tiềm ẩn trên 95 nghiên cứu ở các quốc gia có thu nhập thấp và trung bình $(51,1 \%)$, và cao hơn đối với tỷ lệ trong nhóm người tiếp xúc hộ gia đình ở 108 nghiên cứu ở các quốc gia có thu nhập cao $(28,1 \%)$ [6].

Tỷ lệ hoàn thành điều trị lao tiềm ẩn ở nghiên cứu tại Quảng Nam, Đà Nắng là $85,8 \%$ nếu tính trong nhóm người đồng ý điêu trị (416/485), và là $25,6 \%$ tính trên tỷ lệ luỹ kế cho toàn chuối đa bậc. Trong khi đó, tỳ lệ được phân tích từ 58 nghiên cứu khác được ghi nhận là 18,8\% [4], và trong nghiên cứu ở Brazil là 16.3\% [5]. Mặc dù kết quả có cao hơn một số nghiên cứu khác trên thế giới, nghiên cứu ở Quảng Nam và Đà Nẵng cũng chỉ ra một tỷ lệ đáng kể người tiếp xúc được chỉ định điều trị lao tiềm ẩn tữ chối điều trị $(11,5 \%)$ và một tỷ lệ bỏ trị trong số những bệnh nhân lao tiềm ẩn đã tiến hành điều trị $(12,6 \%)$. Những rào cản dẫn đến thực trạng này bao gồm (i) không tin tưởng hiệu quả điều trị lao tiềm ẩn, (ii) thời gian điều trị lao tiềm ẩn kéo dài, và (iii) xảy ra phản ứng bất lợi của thuốc điều trị lao tiềm ẩn. Những rào cản này cũng được báo cáo tương tự ở một số nghiên cứu về tuân thủ điêu trị lao tiềm ẩn [7].

Thời gian điêu trị lao tiềm ẩn kéo dài và xảy ra tác dụng phụ khi sử dụng phác đồ 6 tháng điều trị hàng ngày bằng Isoniazid cho trẻ con và 
9 tháng điều trị hàng ngày bằng Isoniazid cho người lớn (6-9H) cũng là một cản trở đối với chấp nhận điều trị hoặc dẫn đến bỏ trị, mặc dù tỷ lệ hoàn thành điều trị $(85,8 \%)$ trong nghiên cứu ở Quảng Nam và Đà Nắng đang cao hơn đáng kể hoặc tương đương khi so với một số nghiên cứu khác trên thế giới. Một tổng quan hệ thống năm 2012 so sánh phác đồ điều trị hàng ngày bằng Rifampicin và Isoniazid trong 3-4 tháng (3-4RH) với phác đồ điêu trị hàng ngày bằng Isoniazid trong 6 đến 9 tháng $(6-9 \mathrm{H})$ cho thây tỷ lệ xảy ra tác dụng phụ của công thức 6$9 \mathrm{H}$ cao hơn đáng kể so với cổng thức $3-4 \mathrm{RH}, \mathrm{cu}$ thể, tỷ lệ xuất hiện rối loạn dạ dày là $6,5 \%$ ở công thức $9 \mathrm{H}$ trong khi chỉ là $0,7 \%$ ở công thức $4 \mathrm{RH}$, tỷ lệ tăng men gan $6 \%$ ở nhóm điều trị bằng công thức $9 \mathrm{H}$ so với $1,2 \%$ ở nhóm điều tri bằng công thức $4 R H(p<0.0001)$. Đối với tỷ lệ hoàn thành và tuân thủ điều trị, tỷ lệ hoàn thành điều trị trong nhóm áp dụng công thức $4 R \mathrm{RH}$ là $92 \%$ trong khi tỷ lệ này ở nhóm điều trị bằng công thức $9 \mathrm{H}$ là $86 \%$, tỷ lệ hoàn thành điều trị trong nhóm áp dụng công thức 3RH cao hơn đáng kể so với nhóm áp dụng công thức $6 \mathrm{H}$ $(66,7 \%$ so với $27,6 \%)[8]$.

Các nghiên cứu khác trên thế giới cũng đã chứng minh không có khác biệt về hiệu quả trong dự phòng phát triển thành bệnh lao hoạt động ở những người mắc lao tiềm ẩn sử dụng công thức $6-9 \mathrm{H}$ hay các công thức ngắn hạn thay thế (3-4RH, 3HP). Trong khi đó, các công thức ngắn hạn, đặc biệt là phác đồ 3HP (12 liều điêu trị bằng Rifapentin và Isoniazid, mỗi tuần 1 liêu trong vòng 3 tháng) đơn giản hơn, ngắn hơn và ít liêu hơn rõ rệt. Các bằng chứng đã chỉ ra những người sử dụng phác đồ $3 \mathrm{HP}$ có tỷ lệ hoàn thành điêu trị cao hơn những người sử dụng phác đồ 6-9H [8].

Những phân tích từ kết quả nghiên cứu đã gợi ý những thay đổi về chính sách nên thực hiện khi những can thiệp đa bậc quản lý lao tiềm ẩn được mở rộng và được ưu tiên trong chiến lược cửa Chươning trình chống lao. Đó là vẫn ưu tiên công tác truyên thông, tư vấn về lao, lao tiềm ẩn với các hình thức đa dạng, đặc biệt, quan tâm đến hoạt động tư vấn trực tiếp của cán bộ y tế đối với bệnh nhân và người nhà bênh nhân; nghiên cứu áp dụng các công thức điều trị lao tiềm ẩn ngắn hơn, với mong muốn cung cấp cho người dân những dịch vụ thuận tiện và hiệu quả nhất; và xây dựng cơ chế giám sát tuân thủ điều trị lao tiềm ẩn, giao nhiệm vụ cho cán bộ y tế xã cũng như phối hợp với các tổ chức đoàn thể trong cộng đồng.

\section{KẾT LUẬN}

Những can thiệp y tế công cộng về sàng lọc, chẩn đoán và điều trị lao tiềm ẩn tại Quảng Nam và Đà Nẵng đã có những tác động rất tích cực đến toàn bộ các giai đoạn của chuối đa bậc quản lý lao tiềm ẩn tại các địa bàn can thiệp. Đối tượng tham gia sàng lọc và điều trị lao tiềm ẩn được mở rộng ra người tiếp xúc với bệnh nhân chỉ điểm ở tất cả các nhóm tuổi, được xét nghiệm Mantoux để xác nhận khả năng nhiễm lao tiềm ẩn trước khi được chỉ định điều trị. Quá trình sàng lọc lao tiềm ẩn cũng đã góp phần chẩn đoán và phát hiện sớm bệnh lao để đưa vào điều trị kịp thời, giúp chấm dứt nguồn lây trong cộng đồng.

Từ những kết quả của nghiên cứu tại Quảng Nam và Đà Nẵng, các can thiệp y tế cổng cộng nhằm tăng cường tỷ lệ tham gia vào các giai đoạn của chuỗi đa bậc cung cấp dịch vụ chẩn đoán và điều trị lao tiềm ẩn nên được mở rộng, trở thành một chiến lược quan trọng trong Chương trình chống lao Quốc gia, góp phần thực hiện mục tiêu thanh toán bệnh lao năm 2030 ở Việt Nam.

\section{TÀI LIẸU THAM KHẢO}

1. WHO, Latent Tuberculosis Infection, Updated and consolidated guideline for programmatic management, 2018.

2. Guy B. Marks, Nguyen Viet Nhung, Nguyen Thu Anh, Nguyen Binh Hoa et al. Prevalence of latent tuberculous infection among adults in the general population of Ca Mau, Viet Nam

3. Chương trình chống lao Quốc gia, Báo cáo tổng kêt hoạt động Chương trình chống lao năm 2012, 2013, 2014, 2015, 2016, 2017.

4. Alsdurf H., Hill PC, Matteelli A và cs. The cascade of care in diagnosis and treatment of latent tuberculosis infection: a systematic review and meta-analysis. Lancet ID, 2016.

5. Anneliese Domingues Wysocki, Tereza Cristina Scatena Villa, Tiemi Arakawa và cs. Latent Tuberculosis Infection Diagnostic and Treatment Cascade among Contacts in Primary Health Care in a City of Sao Paulo State, Brazil: Cross-Sectional Study. Published online 2016 Jun 10.

6. Fox GJ, Barry SE, Britton WJ, Marks GB. Contact investigation for tuberculosis: a systematic review and meta-analysis. Eur Respir J 2013

7. Linda Hill Elaine Blumberg, Carol Sipan et al. Multi-Level Barriers to LTBI Treatment: A Research Note. Published online 2008 Dec 16.

8. Hamada Y1, Ford N2, Schenkel K1, et al. Three-month weekly rifapentine plus isoniazid for tuberculosis preventive treatment: a systematic review. Int J Tuberc Lung Dis. 2018 Dec 1;22(12):1422-1428. doi: 10.5588/ijtld.18.0168. 